A N N A L E S Annales de Bretagne et des Pays de l'Ouest

\title{
L'Électeur en campagnes dans le Finistère
}

Jean-François Tanguy

\section{OpenEdition}

Journals

Édition électronique

URL : http://journals.openedition.org/abpo/2444

DOI : $10.4000 /$ abpo. 2444

ISBN : 978-2-7535-2129-2

ISSN : 2108-6443

Éditeur

Presses universitaires de Rennes

Édition imprimée

Date de publication : 30 juin 2012

Pagination : 217-219

ISBN : $978-2-7535-2127-8$

ISSN : 0399-0826

Référence électronique

Jean-François Tanguy, «L'Électeur en campagnes dans le Finistère ». Annales de Bretagne et des Pays de I'Ouest [En ligne], 119-2 | 2012, mis en ligne le 30 juin 2012, consulté le 09 juillet 2020. URL : http:// journals.openedition.org/abpo/2444

Ce document a été généré automatiquement le 9 juillet 2020

(c) Presses universitaires de Rennes 


\title{
L'Électeur en campagnes dans le Finistère
}

\author{
Jean-François Tanguy
}

\section{RÉFÉRENCE}

Le Gall, Laurent, L'Électeur en campagnes dans le Finistère. Une Seconde République de BasBretons, Paris, Les Indes savantes, 2009, 880 p. (ISBN 978-2-84654-231-9).

1 C'est un monument plutôt rare dans le monde de l'édition qu'ont publié en 2009 les Indes savantes : 880 pages en typographie serrée, les citations encore plus que le texte, version remaniée mais guère allégée de la thèse de doctorat de Laurent Le Gall, sous le titre L'Électeur en campagnes dans le Finistère. Une Seconde République des Bas-Bretons. Il s'agit d'un travail proprement colossal principalement centré sur l'année 1848, basculement majeur de l'Histoire avec l'introduction du suffrage universel masculin. À certains égards, cette publication était une gageure, reconnue par l'auteur en termes malgré tout réticents : « En acceptant de publier ce gros livre, Pierre Borella et Frédéric Mantienne ont fait le pari que des thèses-à-plus-de-huit-cent-mille-signes peuvent voir le jour.» (p. 5). Étrange formule : l'ouvrage ne compte pas 800000 ni même un million de signes mais plus de quatre millions... Le vertige de l'auteur devant sa propre production mériterait un long commentaire qu'on ne fera pas ici.

2 Passons au fond de la question: l'histoire du suffrage et des élections, des tendances politiques fondées sur le territoire et des explications de ces phénomènes n'est pas un domaine vraiment nouveau de l'histoire et remonte au moins à André Siegfried en passant par Maurice Agulhon et la République au village, par Raymond Huard, Michel Offerlé, Pierre Rosanvallon et beaucoup d'autres. Mais la thèse de L. Le Gall n'a quand même pas beaucoup d'antécédents repérables par son étude quasiment entomologique du Finistère dans les premiers mois de la Seconde République, éclairée par quelques coups de projecteur sur le passé censitaire d'après 1830 et par une exploration, qui n'occupe qu'une part petite mais précieuse de l'ensemble du volume, des mois de la 
République conservatrice (après le printemps 1849) et encore plus du temps du coup d'État et de ses lendemains.

3 Étudier le Finistère à la lumière des événements de 1848, et surtout du suffrage universel nouveau, peut sembler un défi: la Bretagne, et encore plus la «Basse", semblent avoir depuis longtemps gagné leur place, une place définitive, dans les représentations collectives des tendances politiques du xix siècle et du premier $\mathrm{xx}^{\mathrm{e}}$ siècle. Au commencement, comme dit la Bible, il y eut la Chouannerie et l'adhésion massive à l'Église militante dressée contre l'hydre révolutionnaire. Que le Finistère ait au fond fort peu "chouanné », infiniment moins que le Morbihan, l'est de l'ille-etVilaine ou la Mayenne, a peu d'importance dans ces représentations. À la fin des temps (c'est-à-dire aujourd'hui), il y eut le basculement quasi total de la Bretagne dans le camp socialiste, à partir de 1977 mais de plus en plus marqué d'élection en élection, faisant de la région un des principaux bastions de la gauche française, sans doute pour très longtemps (rappelons que le département de Cadoudal a élu en septembre 2011, trois sénateurs socialistes à la grande surprise des observateurs!), phénomène dont l'explication n'est qu'à peine esquissée. Entre l'alpha et l'oméga, la Bretagne aurait été conforme à la description canonique d'A. Siegfried, une région blanche ou plutôt, comme le dit L. Le Gall "noire ", inébranlable, parsemée d'îlots "bleus " ou même, rarement, «rouges» ("Brest la Rouge »). Que les choses ne soient pas aussi simples a déjà bien sûr été remarqué (Patrick Pierre, Les Bretons et la République, Rennes, PUR, 2001).

4 Concrètement, étudier les effets du suffrage universel, lors de son introduction dans le Finistère, n'était cependant pas sans intérêt. Voilà un territoire dont la grande majorité des électeurs potentiels sont illettrés, dont la quasi-totalité s'exprime couramment en langue étrangère - étrangère à l'idiome français dominant (le breton) -, dont beaucoup ne parlent pas le français, qui ne lisent pas, et à qui l'on donne brusquement un bulletin de vote pour choisir conseillers municipaux, conseillers d'arrondissement, conseillers généraux, députés, et même en décembre 1848 le président de la République. Qu'en ont-ils fait? Qu'est-ce que cela signifiait pour eux ? La façon dont la France a créé en 1848 le suffrage universel est, rappelons-le, sans aucun équivalent au monde. Partout ailleurs, le passage s'est fait progressivement des modes d'élection ordinaux ou corporatifs d'Ancien Régime au suffrage restreint ou censitaire puis à un suffrage presque universel qui a longtemps exclu des catégories plus ou moins vastes (illettrés en Italie, domestiques en Grande-Bretagne, Noirs aux États-Unis) sans parler des femmes pour qui longtemps le problème ne s'est pas posé. Donc, annoncer, en quelque sorte (nous synthétisons) : «Désormais, pauvres, mendiants, illettrés, et vous autres bien sûr, tous autant que vous êtes, vous pouvez voter pour choisir tant votre maire (indirectement) que votre chef d'État ", était une rupture dans le réel qui ne peut être sous-estimée. L'ultime phrase de la conclusion constitue à cet égard une belle sentence riche de portées multiples : «La République au village : quoi de neuf ? Dans le Finistère, ce fut le suffrage. Presque simplement. » (p. 800).

5 L'apport principal de l'ouvrage est de montrer les ambiguïtés, parfois les apories consécutives à l'instauration du suffrage universel, apories qu'il fallait bien assumer vaille que vaille, et d'établir l'impossibilité de classer brutalement les comportements induits par ce suffrage selon des catégories qui nous seraient propres. Les élections se font-elles "réactionnaires " contre "progressistes ", "cléricaux " contre "laïcs ", «élites » contre " peuple »? Peut-on isoler des cantons, des régions votant d'une façon 
ou d'une autre sur le moyen terme? Le vote est-il communautaire ou individuel ? Le grand mérite de L'Électeur en campagnes consiste dans la confrontation de toutes ces hypothèses avec la réalité pour aboutir à la conclusion qu'il est impossible de plaquer de telles configurations sur les choses en train de se faire. Non qu'au bout du compte Laurent Le Gall en arrive à la conclusion qu'on ne peut pas tirer de conclusions. S'il avait fallu 800 pages pour démontrer qu'à la fin des fins, Chaos est maître et souverain de toutes choses, c'eût été à désespérer de tout effort humain. Mais les choses sont toujours plus compliquées qu'on ne le croit, ou qu'on ne veut le croire par paresse intellectuelle. Un exemple : on sait que la monarchie de Juillet avait institué, par la loi du 21 mars 1831, un droit de suffrage censitaire élargi pour les élections municipales et très élargi pour les petites communes. Ce système avait abouti à la formation d'une élite édilitaire assez marquée, " aux affaires » depuis dix-sept ans. Or, l'institution du suffrage universel, bien loin d'aboutir à son renversement ou à son éclatement, entraîna plutôt un renforcement et une concentration du pouvoir entre un petit nombre de mains par un processus lui-même complexe, la société finistérienne de 1848 étant fort peu clanique ou clientéliste au sens sociologique classique. Mais les choses sont souvent encore plus compliquées. Le marquage de territoires politiquement identifiables, à la Siegfried, est à la fois difficile à faire depuis le poste d'observation « 1848 » et en même temps pas tout à fait impossible : la constitution du pôle clérical léonard, longtemps inexpugnable (il sera l'un des derniers territoires bretons à résister au « rosissement »; mais, là comme ailleurs, depuis 2001 et 2008, les maires socialistes ou « divers gauche " sont désormais nombreux, sinon majoritaires), peut s'observer de manière encore un peu timide mais nette dès 1849-1850 par le et à cause du suffrage universel.

6 La méthode de l'ouvrage est à maints égards remarquable: l'auteur s'empare à plusieurs reprises de cas individuels, les dissèque parfois à la manière d'un Fabre (l'entomologiste) et de ces conflits entre maire et curé, curé et notaire (qui peut être maire), propriétaire et exploitant, avec appel à l'autorité supérieure, sous-préfet, préfet, conseil de préfecture, tire, non pas de lourdes démonstrations, mais le fil de l'usage que le bulletin de vote va créer dans les comportements interindividuels qui, peu à peu, deviendront des comportements normés et, finalement, politiques. C'est en forgeant qu'on devient forgeron et en votant qu'on devient électeur et qu'on crée, lentement, des choix. Le verbe « élire » est au départ synonyme de " choisir ».

L'ouvrage, écrit en une langue excellente et claire, au rebours de certains politistes ou philosophes, voire historiens qui se croient obligés d'être obscurs pour faire intelligent, pourra certes rebuter par son ampleur même. Rares sont les ouvrages qui peuvent se permettre de faire une citation de quatre pages en petits caractères (p. 547-550). Peutêtre aussi pourra-t-on regretter (regretter que le livre ne fasse pas huit millions de signes ?) de ne voir qu'esquissée la grande opération qui commence en décembre 1851 et qui, à certains égards, dans et à travers un régime césarien et policier, va en vingt ans discipliner, organiser, enraciner le suffrage universel en France, suffrage encore si fragile, incertain et chaotique en 1848 , et ce pour la première fois au monde dans l'ensemble d'un État. Napoléon III, créateur du suffrage universel ? En quelque sorte. 